\title{
Dynamic Changes in Heat Transducing Channel TRPV1 Expression Regulate Mechanically Insensitive, Heat Sensitive C-Fiber Recruitment after Axotomy and Regeneration
}

\author{
Michael P. Jankowski, Deepak J. Soneji, Katrina M. Ekmann, Collene E. Anderson, and H. Richard Koerber \\ Department of Neurobiology, University of Pittsburgh School of Medicine, Pittsburgh, Pennsylvania 15261
}

Peripheral injury leads to a significant increase in the prevalence of mechanically insensitive, heat-sensitive C-fibers $(\mathrm{CH})$ that contain the heat transducing TRPV1 (transient receptor potential vanilloid type I) channel in mice. We have recently shown that this recruitment of $\mathrm{CH}$ fibers is associated with increased expression of the receptor for GDNF (glial cell line-derived neurotrophic factor) family neurotrophic factor artemin (GFR $\alpha 3$ ), and that in vivo inhibition of GFR $\alpha 3$ prevented the increase in TRPV1 expression normally observed following axotomy. Here we have directly tested the hypothesis that the recruitment of functional $\mathrm{CH}$ fibers following nerve regeneration requires enhanced TRPV1 levels. We used in vivo siRNA-mediated knockdown to inhibit the injury-induced expression of TRPV1 coupled with ex vivo recording to examine response characteristics and neurochemical phenotypes of different functionally defined cutaneous sensory neurons after regeneration. We confirmed that inhibition of TRPV1 did not affect the axotomy-induced decrease in polymodal C-fiber (CPM) heat threshold, but transiently prevented the recruitment of $\mathrm{CH}$ neurons. Moreover, a recovery of TRPV1 protein was observed following resolution of siRNA-mediated inhibition that was correlated with a concomitant rebound in $\mathrm{CH}$ neuron recruitment. Thus dynamic changes in TRPV1 expression, not absolute levels, may underlie the functional alterations observed in $\mathrm{CH}$ neurons and may contribute to the development of heat hyperalgesia after nerve injury.

\section{Introduction}

Transient receptor potential vanilloid type I (TRPV1) is a well known heat transducing channel involved in behavioral heat hyperalgesia following peripheral injuries (Caterina et al., 1997, 2000; Davis et al., 2000). We have recently found that this channel is specifically contained in a small subset of murine cutaneous $\mathrm{C}$-fibers that are mechanically insensitive but heat sensitive (CH; Lawson et al., 2008). TRPV1 knock-out mice, which do not develop heat hyperalgesia after inflammation (Caterina et al., 1997), do not have CH fibers (Lawson et al., 2008; Koerber et al., 2010), suggesting that the presence or changes in these particular afferents are crucial for the development of inflammation-induced heat hypersensitivity. Heat hyperalgesia following nerve regeneration has been well documented in humans (Head and Sherren, 1905). In addition we have previously shown that both axotomy and regeneration (Jankowski et al., 2009a) and peripheral inflammation (Jankowski et al., 2012) induce a significant increase in the proportion of functional $\mathrm{CH}$ fibers relative to that seen in uninjured mice, suggesting that changes in these fibers could contribute to heat hyperalgesia in both types of injury.

\footnotetext{
Received July 2, 2012; revised 0ct. 3, 2012; accepted Oct. 27, 2012.

Author contributions: M.P.J. and H.R.K. designed research; M.P.J., D.J.S., K.M.E., and C.E.A. performed research;

K.M.E., C.E.A., and H.R.K. analyzed data; M.P.J. and H.R.K. wrote the paper.

This research was supported by NIH Grants NS 023725, NS 052848 (H.R.K.), and F32 NS 061487 (M.P.J.).

Correspondence should be addressed to Dr. H. Richard Koerber, Department of Neurobiology, University of Pittsburgh School of Medicine, 3500 Terrace Street, Pittsburgh, PA 15261. E-mail: rkoerber@pitt.edu.

DOI:10.1523/JNEUROSCI.3148-12.2012

Copyright $\odot 2012$ the authors $\quad 0270-6474 / 12 / 3217869-05 \$ 15.00 / 0$
}

In our previous studies we have also obtained results suggesting possible mechanisms responsible for this recruitment of normally mechanically and thermally insensitive fibers to $\mathrm{CH}$ fibers. For example, axotomy of the saphenous nerve was found to induce the expression of the GDNF (glial cell line-derived neurotrophic factor) neurotrophic factor family member artemin in the skin with a corresponding increase in its receptor (GFR $\alpha 3)$ in the dorsal root ganglia (DRGs) during nerve regeneration (Bennett et al., 2000; Orozco et al., 2001; Jankowski et al., 2009a). This subsequently caused an increase in TRPV1 expression corresponding with reinnervation (Jankowski et al., 2009a). The change in GFR $\alpha 3$ expression was found to be essential for the observed $\mathrm{CH}$ fiber recruitment after axotomy and regeneration, and this correlated with the delayed increase in TRPV1 expression. Thus we hypothesized that the injury-induced increase in artemin/GFR $\alpha 3$ signaling resulted in increased levels of TRPV1, which in turn was directly responsible for the observed $\mathrm{CH}$ fiber recruitment (Jankowski et al., 2010).

Here, we sought to directly test this hypothesis using our in vivo siRNA knockdown strategy by injecting siRNAs targeting TRPV1 during saphenous nerve regeneration. The effects of the blockade of TRPV1 expression on the functional response properties and neurochemical phenotypes of regenerated fibers was determined using an ex vivo preparation (Jankowski et al., 2009a, 2010).

\section{Materials and Methods}

Animals. Experiments were conducted using adult (4-6 weeks) male Swiss Webster mice (Hilltop Farms). All procedures were approved by 
the Institutional Animal Care and Use Committee at the University of Pittsburgh and used in accordance with institutional AAALAC-approved practices.

Saphenous nerve axotomy. Mice were anesthetized by 3\% isoflurane inhalation. A small incision was made at the mid-thigh level. The saphenous nerve was transected without disturbing the surrounding tissue. The wound was closed using 7.0 silk sutures and animals were allowed to survive for $28-84 \mathrm{~d}$.

siRNA injections. siRNAs were designed and conjugated to Penetratin-1 (Pen-siRNA) as described previously (Davidson et al., 2004; Jankowski et al., 2006, 2009b, 2010). Mice were anesthetized as described above and the previously transected saphenous nerve was exposed proximal to the lesion. Pen-siRNAs were first heated to $65^{\circ} \mathrm{C}$ for $5 \mathrm{~min}$ to increase solubility. Then at 2 and 3 weeks after cutting the nerve, $0.1-0.2$ $\mu \mathrm{l}$ of $90 \mu \mathrm{M}$ Penetratin-1-linked control (PenCON) or TRPV1-targeting (PenV1) siRNAs were injected into the saphenous nerve (Jankowski et al., 2009b).

RNA isolation and real-time PCR. Animals were anesthetized with a mixture of ketamine $(90 \mathrm{mg} / \mathrm{kg})$ and xylazine $(10 \mathrm{mg} / \mathrm{kg})$ and perfused with ice-cold $0.9 \% \mathrm{NaCl}$ before dissection of DRGs. RNA isolation from the L2/L3 DRGs, reverse transcription and SYBR Green real-time PCR was performed according to our previous reports (Jankowski et al., 2009a,b, 2010, 2012). Expression of TRPV1, GFR $\alpha 3$, Sox11, ATF3 and GAPDH were analyzed. Ct values for genes of interest were normalized to GAPDH and changes in expression are calculated as a $\Delta \Delta_{\mathrm{Ct}}$ value according to the manufacturer's specifications. Fold change is described as $2^{\Delta \Delta \mathrm{Ct}}$ (Applied Biosystems) and twofold change equals 100\% change.

Western blot. Pooled L2/L3 DRGs from eight naive and eight nerve injured mice from each experimental condition and time point were used for Western blotting analysis according to modified protocols described in our previous reports (Jankowski et al., 2009a,b, 2010, 2012). After transfer, polyvinylidene difluoride membranes were incubated first in a 1:1 mixture of LI-COR blocking buffer and PBS and then in primary antibodies overnight at $4^{\circ} \mathrm{C}$ (TRPV1: 1:100, Santa Cruz Biotechnology; GAPDH: 1:2000, ProSci Inc.). Antibody binding was visualized using 680 $\mathrm{nm}$ or $800 \mathrm{~nm}$ infrared dye-conjugated donkey anti-rabbit or donkey anti-chicken secondary antibodies (1:10,000, LI-COR) and detection using the LI-COR Odyssey Imager. Settings for detection were consistent between runs with the gain set at 1.0. Immunoreactive bands were analyzed by densitometry and quantified using NIH ImageJ analysis software. Band intensity was normalized to GAPDH and reported as a percentage change.

Ex vivo preparation. The ex vivo preparation has been described previously (McIlwrath et al., 2007; Lawson et al., 2008). Briefly, mice were anesthetized (Ketamine, $90 \mathrm{mg} / \mathrm{kg}$ and Xylazine, $10 \mathrm{mg} / \mathrm{kg}$, i.m.) and transcardially perfused with oxygenated $\left(95 \% \mathrm{O}_{2}-5 \% \mathrm{CO}_{2}\right)$ artificial CSF (aCSF; in mm: $1.9 \mathrm{KCl}, 1.2 \mathrm{KH}_{2} \mathrm{PO}_{4}, 1.3 \mathrm{MgSO}_{4} 2.4 \mathrm{CaCl}_{2}, 26.0 \mathrm{NaHCO}_{3}$, and $10.0 \mathrm{D}$-glucose) containing $253.9 \mathrm{~mm}$ sucrose at $12-15^{\circ} \mathrm{C}$. The spinal cord and right hindlimb was excised and placed in a circulating bath of oxygenated aCSF. Hairy skin of the right hindpaw, saphenous nerve, T13-L5 DRGs and spinal cord was isolated and transferred to a separate recording chamber containing chilled oxygenated aCSF in which the sucrose was replaced with $127.0 \mathrm{~mm} \mathrm{NaCl}$ and warmed to $31^{\circ} \mathrm{C}$. The skin was pinned out on a stainless steel grid located at the bath/air interface while the epidermis stayed dry.

DRG cells were impaled with quartz microelectrodes containing 5\% Neurobiotin (Vector Laboratories) in $1 \mathrm{~m}$ potassium acetate. Electrical search stimuli were delivered through a suction electrode on the nerve. Cutaneous receptive fields (RFs) were localized with a blunt glass stylus and von Frey hairs. When no mechanical RF was found, a thermal search was conducted by applying cold $\left(\sim 0^{\circ} \mathrm{C}\right)$ then hot $\left(\sim 52^{\circ} \mathrm{C}\right)$ saline to the skin.

Response characteristics were determined by first applying computercontrolled mechanical stimulation (Aurora Scientific) using a 1-mmdiameter plastic disc: $5 \mathrm{~s}$ square waves of $1,5,10,25,50$, and $100 \mathrm{mN}$ were applied to the RF. Next a digitally controlled thermal stimulus was applied using a $3 \mathrm{~mm}^{2}$ contact area Peltier element (Yale University Machine Shop). Thermal stimulus consisted of rapid cooling to $4^{\circ} \mathrm{C}$, return to baseline, then a $12 \mathrm{~s}$ heat ramp from 31 to $52^{\circ} \mathrm{C}$. A $30 \mathrm{~s}$ recovery was used between stimulations. Recorded responses were analyzed offline (Spike2 software, Cambridge Electronic Design). Selected cells were iontophoretically labeled with Neurobiotin. Peripheral conduction velocity was calculated using spike latency and the distance between stimulating and recording electrodes.

Tissue processing and analysis of recorded cells. DRGs containing injected cells were immersion fixed with $4 \%$ paraformaldehyde in $0.1 \mathrm{M}$ phosphate buffer for $30 \mathrm{~min}$ at $4^{\circ} \mathrm{C}$. Ganglia were embedded in $10 \%$ gelatin, postfixed in $4 \%$ paraformaldehyde, and cryoprotected in $20 \%$ sucrose. Frozen sections $(60 \mu \mathrm{m})$ were reacted with fluorescently tagged (fluorescein isothiocyanate) avidin to label Neurobiotin-filled cells (Vector Laboratories) and processed for IB4 binding (Alexa Fluor 647; Invitrogen) and TRPV1 (1:2000; Alomone) immunohistochemistry. Fluorescent staining was determined using sequential scanning on an Olympus FluoView 500 confocal microscope (Olympus America Inc).

Data analysis. One-way ANOVA and post hoc analysis (Tukey) were used to analyze differences in firing rate along with mechanical and thermal thresholds. Differences in fiber prevalence and immunostaining were determined by Fisher's Exact analysis. Percentage changes in mRNA were determined to be statistically significant by ANOVA with post hoc analysis (Tukey). Statistical analyses were performed on raw Ct data and represented for ease of presentation as a percentage change. $p$-values were set at $p<0.05$.

\section{Results}

We first verified that TRPV1 gene expression could be specifically inhibited by PenV1 siRNAs injected into the saphenous nerve after axotomy. At $28 \mathrm{~d}$ following axotomy and regeneration, TRPV1 mRNA was found to be significantly increased in the DRGs after injection of nontargeting (PenCON) siRNAs (36 \pm $13 \%)$, similar to what had previously been shown after axotomy alone (Jankowski et al., 2009a). Injection of targeting PenV1 siRNAs significantly inhibited the axotomy-induced increase in TRPV1 mRNA ( $-13 \pm 5 \%$; Fig. $1 A)$. At the $70 \mathrm{~d}$ time point, however, both PenCON injection plus axotomy $(74 \pm 15 \%)$ and PenV1 plus axotomy $(52 \pm 10 \%)$ showed enhanced levels of TRPV1 in the DRGs relative to naive mice, similar to the levels detected after axotomy alone ( $87 \pm 21 \%$; Jankowski et al., 2009a; Fig. $1 B)$. RT-PCR results were then verified at the protein levels (Fig. 1C,D; 28 d: Axotomy, 25\%; PenCON plus axotomy, 43\% and PenV1 plus axotomy, $-32 \%$; $70 \mathrm{~d}$ : Axotomy, 49\%; PenCON plus axotomy, $32 \%$ and PenV1 plus axotomy, 47\%).

\section{TRPV1 knockdown does not alter the axotomy-induced decrease in polymodal C-fiber heat threshold}

A total of 225 cutaneous sensory neurons were intracellularly recorded and physiologically characterized from 40 nerve injured adult Swiss-Webster mice. The results from these two experimental groups were compared with each other and to previously published results from naive and axotomized SW mice (Jankowski et al., 2009a). Neurons with a conduction velocity of $<1.2 \mathrm{~m} / \mathrm{s}$ were classified as C-fibers (Kress et al., 1992) and all others were classified as A-fibers. For these experiments we have focused our analyses specifically on the population of regenerated C-fibers.

We found no statistical difference between time points (4-6 and 10-12 weeks) for each of the experimental conditions in relation to polymodal C-fiber (mechanical and heat or mechanical, heat and cold sensitive) mechanical threshold, heat threshold or maximal firing rate during the heat ramp; therefore the data are combined for ease of presentation. After regeneration of the saphenous nerve in PenCON-injected mice, CPM thermal thresholds were significantly reduced to $39.1 \pm 0.6^{\circ} \mathrm{C}(p<0.01)$ compared with previous naive data $\left(42.6 \pm 0.5^{\circ} \mathrm{C}\right)$; similar to that seen after axotomy alone $\left(39.2 \pm 0.7^{\circ} \mathrm{C}\right.$; Jankowski et al., 2010). A 

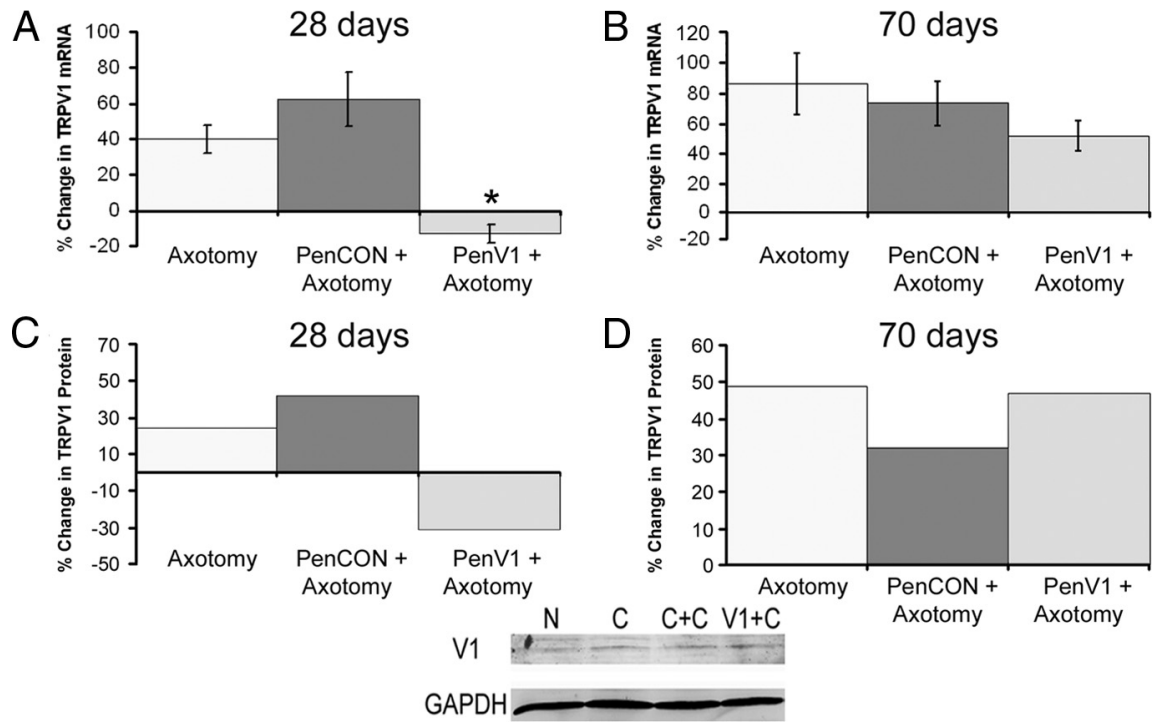

Figure 1. Real-time PCR and Western blotting analysis of DRGs 28 and $70 \mathrm{~d}$ after axotomy of the saphenous nerve with or without injection of PenCON or PenV1 siRNAs. Injection of PenV1 siRNAs prevented the significant injury-induced increase in TRPV1 mRNA in L2/L3 DRGs at $28 \mathrm{~d}$ after axotomy and axotomy plus PenCON injection relative to naive mice (A). At $70 \mathrm{~d}$ post-axotomy, TRPV1 mRNA was increased under all experimental conditions $(\boldsymbol{B})$. Western blot analysis verified that changes in mRNA under each condition at both time points corresponded to an increase in protein expression $(\boldsymbol{C}, \boldsymbol{D})$. Inset, Example of Western blots for pooled DRGs from 8 naive mice and 8 mice after nerve cut with or without siRNA injection (N, Naive; C, Axotomy alone; $C+C$, PenCON + Axotomy; $\mathrm{V} 1+\mathrm{C}$, PenV1 + Axotomy). Axotomy without injection data in A and B are from Jankowski et al. (2009a). ${ }^{*} p<0.05$, relative to axotomy and PenCON plus axotomy. All other conditions were statistically different from naives $(p<0.05)$.
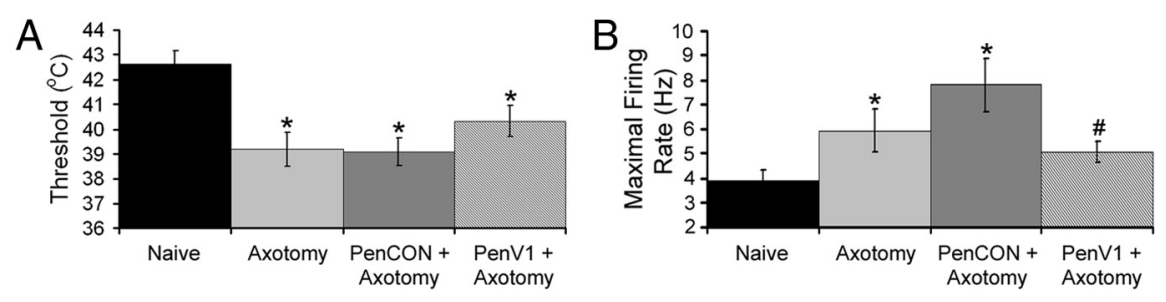

Figure 2. Heat thresholds and maximal firing rates of CPM neurons after axotomy. CPMs showed a significant reduction in heat threshold relative to naive CPMs $(n=60)$ after axotomy $(n=41)$ and with injection of PenCON plus axotomy $(n=44)$ or injection of PenV1 siRNAs plus axotomy ( $n=57$; Combined data from both 4- to 6 - and 10- to 12-week time points; $A,{ }^{*} p<0.001$ ). The average maximal firing rate over the entire heat ramp was significantly different after axotomy alone $(5.9 \pm 0.9 \mathrm{~Hz} ; p<0.02)$ and PencoN plus axotomy $(7.8 \pm 1.1 \mathrm{~Hz} ; p<0.001)$ relative to naives $(3.9 \pm 0.4 \mathrm{~Hz})$; however, inhibition of TRPV1 $(5.1 \pm 0.5 \mathrm{~Hz} ; p<$ 0.06 ) blocked the injury-induced increase in maximal firing rate in these fibers $(\boldsymbol{B})$. "Firing rate is not significantly increased from naives $(p<0.06)$ or different from axotomy alone $(p<0.3)$. Data for naive (Jankowski et al., 2009a) and axotomy only (Jankowski et al., 2010) conditions used for comparisons were obtained from previous data under the same experimental conditions.

comparable reduction in threshold was detected in mice that received PenV 1 siRNA injection $\left(40.3 \pm 0.6^{\circ} \mathrm{C} ; p<0.01\right.$; Fig. $\left.2 A\right)$. The maximal firing rate of CPM neurons during the heat ramp was increased after PenCON plus axotomy $(7.8 \pm 1.1 \mathrm{~Hz} ; p<$ $0.01)$ relative to naives $(3.9 \pm 0.4 \mathrm{~Hz})$ similar to the significant increase shown after axotomy alone $(5.9 \pm 0.9 \mathrm{~Hz}$; Jankowski et al., 2010). While the maximal firing rate of CPM neurons was still elevated in mice injected with PenV1 siRNAs plus axotomy, it was not significantly different from naive values $(5.1 \pm 0.5 \mathrm{~Hz} ; p=$ 0.06; Fig. $2 B$ ). Importantly the increase in firing rate was not different from that observed following axotomy alone $(p=0.3)$. Consistent with our previous reports (Jankowski et al., 2009a, 2010), CPM mechanical threshold was not altered under any condition (Naive: $20.8 \pm 2.2 \mathrm{mN}$; Axotomy: $24.2 \pm 3.8 \mathrm{mN}$; PenCON plus axotomy: $24.2 \pm 4.8 \mathrm{mN}$; PenV1 plus axotomy: $25.2 \pm 3.2 \mathrm{mN})$.
TRPV1 knockdown alters the recruitment of $\mathrm{CH}$ neurons induced by axotomy and regeneration

$\mathrm{CH}$ fibers showed no significant changes in thermal threshold at any time points tested after axotomy under any condition (Naive: $41.0 \pm 1.6^{\circ} \mathrm{C}$; Combined Time Points: Axotomy, $44.0 \pm 1.3^{\circ} \mathrm{C}$; PenCON + Axotomy, $39.6 \pm 1.9^{\circ} \mathrm{C}$; PenV1 + Axotomy, $37.9 \pm 1.9^{\circ} \mathrm{C} ; p<0.2$ relative to naives). As shown previously following axotomy alone (Jankowski et al., 2009a, 2010) 4-6 weeks after nerve cut, there was a significant increase in the proportion of $\mathrm{CH}$ fibers relative to naive mice in the PenCON plus axotomy condition $(5 \%$ vs $18 \%$; $p<0.02)$. This recruitment of $\mathrm{CH}$ fibers after axotomy however, was blocked by inhibition of TRPV1 expression (PenV1 + Axotomy: 10\%; $p<0.1)$ at this time point (Fig. $3 A-C$ ). However, at the 10- to 12-week time point (Fig. 3D,E), the proportion of $\mathrm{CH}$ fibers was significantly increased in this group $(18 \% ; p<$ 0.02 ), matching that seen in axotomy alone (Jankowski et al., 2009a, 2010) and PenCON plus axotomy $(23 \%$; $p<0.001)$. This rebound in $\mathrm{CH}$ fibers corresponded with the rebound of TRPV1 levels at this later time point (Fig. 1).

Immunohistochemical characterization of cutaneous $\mathrm{CPM}$ and $\mathrm{CH}$ neurons after regeneration

A total of 39 C-fibers were intracellularly labeled, recovered and imunohistochemically characterized in nerve injured mice from the two conditions. There were no differences in immunolabeling for either marker between time points under any condition; therefore, we combined immunostaining results from the time points for ease of presentation. Overall, most CPM fibers (7 of 12) bound IB4 in mice with PenCON siRNA injection plus axotomy and 12 of $18 \mathrm{CPM}$ neurons bound IB4 in the PenV1 plus axotomy condition. Surprisingly, 8 of 13 CPM neurons under control conditions were immunoreactive for TRPV 1 , which was significantly higher than that observed following axotomy plus PenV1 injections (4 of 18 CPMs were TRPV1 positive). This percentage of TRPV1-positive CPM fibers following PenCON injections here was also significantly higher than that observed previously following axotomy alone (Jankowski et al., 2009a) and axotomy plus PenCON injections which used a different injection paradigm (Jankowski et al., 2010).

The increase in TRPV1 + CPM fibers following control siRNA injection raised the possibility that this injection paradigm (i.e., injections at 2 and 3 weeks after axotomy) may have resulted in additional damage possibly accelerating the gain of mechanical sensitivity in these previously mechanically insensitive $\mathrm{CH}$ fibers. We thus examined the expression of two transcription factors, Sox11 and ATF3, whose expression levels are known to increase 
dramatically following nerve injury (Tsujino et al., 2000; Jankowski et al., 2006, 2009a) and two receptors, GFR $\alpha 3$ and P2Y1, that have been shown to play a role in the gaining of mechanical sensitivity by these fibers (Jankowski et al., 2010, 2012). However, we found no changes in the expression of these genes in the L2,3 DRG at 4 weeks after axotomy with PenCON injections at 2 and 3 weeks compared with axotomy alone (Sox11 $-2 \pm 13 \%$; ATF3 $-17 \pm 30 \%$; GFR $\alpha 3-1 \pm 17 \%$; P2Y1 $11 \pm 22 \% ; n=4$ for all comparisons). We also were able to verify previous data on $\mathrm{CH}$ neurons as all of these fibers (six) under both conditions stained positively for TRPV1 (Lawson et al., 2008; Jankowski et al., 2009a, 2010).

\section{Discussion}

It has been previously shown that enhanced artemin levels in the skin can regulate TRPV1 expression in the DRGs (Elitt et al., 2006). We and others have also previously shown that peripheral nerve axotomy increased artemin levels in the skin and increased levels of its receptor GDNF family receptor $\alpha 3$ (GFR $\alpha 3)$ in the appropriate DRGs (Bennett et al., 2000; Jankowski et al., 2009a, 2010). In addition, we found that by 4 weeks after nerve cut, there was a significant increase in the expression of TRPV1 (Jankowski et al., 2009a). Recently we have shown that inhibition of the axotomy-induced increase in GFR $\alpha 3$ blocked the observed recruitment of $\mathrm{CH}$ neurons and the increase in TRPV1 expression following regeneration (Jankowski et al., 2010). These results suggested that putative enhanced signaling through the artemin/GFR $\alpha 3$ pathway after regeneration caused changes in TRPV1 expression, leading to $\mathrm{CH}$ neuron recruitment.

Here, using a previously established in vivo siRNA-mediated knockdown strategy (Jankowski et al., 2009b), we tested whether the increase in TRPV1 expression alone could be responsible for $\mathrm{CH}$ neuron recruitment after regeneration. In vivo siRNAmediated inhibition of injury-induced changes in TRPV1 expression blocked the normal recruitment of $\mathrm{CH}$ neurons without altering the injury-induced decrease in CPM heat threshold 4 weeks after injury. Interestingly, upon rebound of the expression of TRPV1 in the DRGs at 10-12 weeks, we found a recovery of $\mathrm{CH}$ neuron recruitment in the mice that received TRPV1targeting siRNA injection plus axotomy while the decrease in CPM heat threshold was unaffected. These results in conjunction with our previous report (Jankowski et al., 2010) strongly suggest that dynamic changes in TRPV1 expression and not absolute levels tightly regulate the number of functional $\mathrm{CH}$ neurons in mice after injury.

\section{Changes in TRPV1 expression after regeneration and the acquisition of mechanical sensitivity in the $\mathrm{CH}$ fiber population}

In previous studies we obtained results suggesting that axotomy and successful regeneration (Jankowski et al., 2009a) lead to the acquisition of mechanical sensitivity in normally mechanically insensitive $\mathrm{CH}$ fibers, which is similar to what has been hypoth-
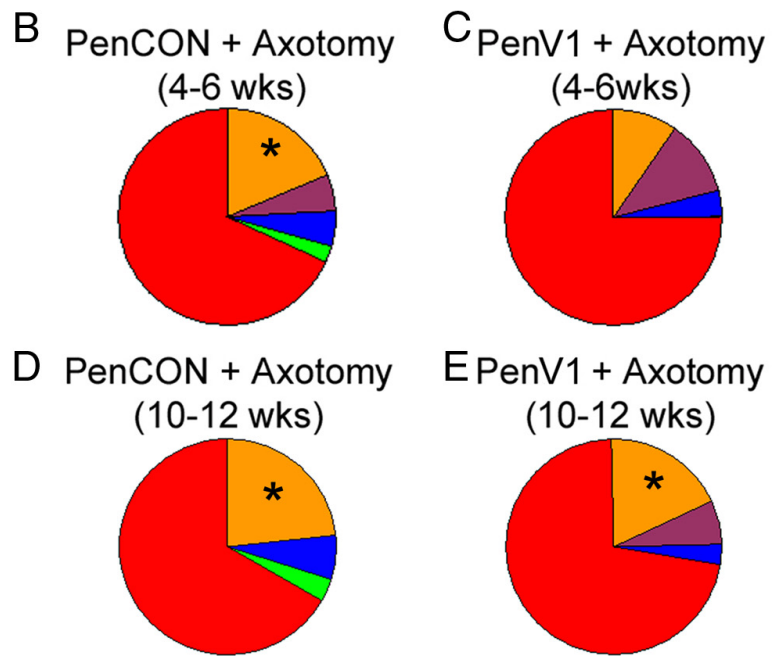

Figure 3. Phenotypes of C-fibers before and after axotomy of the saphenous nerve. $\boldsymbol{A}$, In naive mice, most C-fibers ( $62 \%$ of total) (19\% of total; $p<0.02$ ). Naive condition used for comparison was obtained from previous data (Jankowski et al., 2009a) under the same experimental conditions.

esized in human chronic pain states (Ørstavik et al., 2003). In addition to blocking $\mathrm{CH}$ fiber recruitment, knockdown of the increase in GFR $\alpha 3$ expression following axotomy also blocked this change as no CPM fibers stained positively for TRPV1 (Jankowski et al., 2010). Here we found that TRPV1 knockdown resulted in the same percentage of TRPV1-positive CPM fibers seen following axotomy alone or with axotomy and control siRNA injections in our previous studies (Jankowski et al., 2009a, 2010). This would suggest that the increase in TRPV1 expression following regeneration does not play a major role in the acquisition of mechanical sensitivity. This conclusion is also supported by the fact that following inflammation we have observed the same change in mechanical sensitivity without an apparent change in TRPV1 expression (Jankowski et al., 2012). Together these findings suggest that while dynamic expression of TRPV1 is required for the gaining of heat sensitivity, it does not play a pivotal role in the acquisition of mechanical sensitivity normally seen following peripheral injury (Jankowski et al., 2009a, 2010, 2012).

However, it is important to note that in these experiments, we also observed an increase in TRPV1-positive CPM fibers following control siRNA injections that was significantly higher than the number of such fibers following TRPV1 targeted siRNA injections. Thus, we cannot rule out a potential role for TRPV1 in the gaining of mechanical sensitivity in these fibers. We have examined the possibility that the injection paradigm may have caused additional injury to the nerve which in turn could accelerate the acquisition of mechanical sensitivity. However, there were no changes in the expression of ATF3 or Sox 11 transcription factors suggesting that as we documented in our earlier studies, these injections do not cause any significant injury to the nerve fibers. In addition we have recently suggested two other possible players in this acquisition of mechanical sensitivity; GFR $\alpha 3$ and the purinergic receptor P2Y1. Inhibition of GFR $\alpha 3$ was found to 
completely block the increase in TRPV1-positive CPMs after regeneration (Jankowski et al., 2010) while inhibition of the expression of the P2Y1 receptor after inflammation has been shown to increase the numbers of TRPV1-immunopositive CPM neurons (Jankowski et al., 2012). However, expression levels of neither receptor were altered after the two PenCON injections. On the other hand, we recently hypothesized that in the subpopulation of $\mathrm{CH}$ cells that contain both $\mathrm{P} 2 \mathrm{Y} 1$ and TRPV1, P2Y1 expression may be decreased, but this decrease would not be discernable when measuring expression levels across the whole DRG. Thus it will be important to determine the expression levels in individual characterized cells in the future to fully understand the mechanisms of how this and other subpopulations of sensory neurons may alter peripheral response properties after injury and the receptors that may be involved. Nevertheless, the results presented here strongly suggest that an increase in TRPV1 levels is necessary for the increase in functional $\mathrm{CH}$ neurons following nerve injury and regeneration, but it also appears that this increase in TRPV1 expression is not necessary for these fibers to gain mechanical sensitivity following regeneration.

\section{References}

Bennett DL, Boucher TJ, Armanini MP, Poulsen KT, Michael GJ, Priestley JV, Phillips HS, McMahon SB, Shelton DL (2000) The glial cell line-derived neurotrophic factor family receptor components are differentially regulated within sensory neurons after nerve injury. J Neurosci 20:427-437. Medline

Caterina MJ, Schumacher MA, Tominaga M, Rosen TA, Levine JD, Julius D (1997) The capsaicin receptor: a heat-activated ion channel in the pain pathway. Nature 389:816-824. CrossRef Medline

Caterina MJ, Leffler A, Malmberg AB, Martin WJ, Trafton J, Petersen-Zeitz KR, Koltzenburg M, Basbaum AI, Julius D (2000) Impaired nociception and pain sensation in mice lacking the capsaicin receptor. Science 288: 306-313. CrossRef Medline

Davidson TJ, Harel S, Arboleda VA, Prunell GF, Shelanski ML, Greene LA, Troy CM (2004) Highly efficient small interfering RNA delivery to primary mammalian neurons induces MicroRNA-like effects before mRNA degradation. J Neurosci 24:10040-10046. CrossRef Medline

Davis JB, Gray J, Gunthorpe MJ, Hatcher JP, Davey PT, Overend P, Harries MH, Latcham J, Clapham C, Atkinson K, Hughes SA, Rance K, Grau E, Harper AJ, Pugh PL, Rogers DC, Bingham S, Randall A, Sheardown SA (2000) Vanilloid receptor-1 is essential for inflammatory thermal hyperalgesia. Nature 405:183-187. CrossRef Medline

Elitt CM, McIlwrath SL, Lawson JJ, Malin SA, Molliver DC, Cornuet PK, Koerber HR, Davis BM, Albers KM (2006) Artemin overexpression in skin enhances expression of TRPV1 and TRPA1 in cutaneous sensory neurons and leads to behavioral sensitivity to heat and cold. J Neurosci 26:8578-8587. CrossRef Medline

Head H, Sherren J (1905) The consequences of injury to the peripheral nerves in man. Brain 28:116-338. CrossRef

Jankowski MP, Cornuet PK, McIlwrath S, Koerber HR, Albers KM (2006) SRY-box containing gene 11 (Sox11) transcription factor is required for neuron survival and neurite growth. Neuroscience 143:501-514. CrossRef Medline

Jankowski MP, Lawson JJ, McIlwrath SL, Rau KK, Anderson CE, Albers KM, Koerber HR (2009a) Sensitization of cutaneous nociceptors after nerve transection and regeneration: possible role of target-derived neurotrophic factor signaling. J Neurosci 29:1636-1647. CrossRef Medline

Jankowski MP, McIlwrath SL, Jing X, Cornuet PK, Salerno KM, Koerber HR, Albers KM (2009b) Sox11 transcription factor modulates peripheral nerve regeneration in adult mice. Brain Res 1256:43-54. CrossRef Medline

Jankowski MP, Rau KK, Soneji DJ, Anderson CE, Koerber HR (2010) Enhanced artemin/GFRalpha3 levels regulate mechanically insensitive, heat-sensitive C-fiber recruitment after axotomy and regeneration. J Neurosci 30:16272-16283. CrossRef Medline

Jankowski MP, Rau KK, Soneji DJ, Ekmann KM, Anderson CE, Molliver DC, Koerber HR (2012) Purinergic receptor P2Y1 regulates polymodal C-fiber thermal sensitivity during peripheral inflammation. Pain 153:410-419. CrossRef Medline

Koerber HR, McIlwrath SL, Lawson JJ, Malin SA, Anderson CE, Jankowski MP, Davis BM (2010) Cutaneous C-polymodal fibers lacking TRPV1 are sensitized to heat following inflammation, but fail to drive heat hyperalgesia in the absence of TPV1 containing C-heat fibers. Mol Pain 6:58. CrossRef Medline

Kress M, Koltzenburg M, Reeh PW, Handwerker HO (1992) Responsiveness and functional attributes of electrically localized terminals of cutaneous C-fibers in vivo and in vitro. J Neurophysiol 68:581-595. Medline

Lawson JJ, McIlwrath SL, Woodbury CJ, Davis BM, Koerber HR (2008) TRPV1 unlike TRPV2 is restricted to a subset of mechanically insensitive cutaneous nociceptors responding to heat. J Pain 9:298-308. CrossRef Medline

McIlwrath SL, Lawson JJ, Anderson CE, Albers KM, Koerber HR (2007) Overexpression of neurotrophin-3 enhances the mechanical response properties of slowly adapting type 1 afferents and myelinated nociceptors. Eur J Neurosci 26:1801-1812. CrossRef Medline

Orozco OE, Walus L, Sah DW, Pepinsky RB, Sanicola M (2001) GFRalpha3 is expressed predominantly in nociceptive sensory neurons. Eur J Neurosci 13:2177-2182. CrossRef Medline

Ørstavik K, Weidner C, Schmidt R, Schmelz M, Hilliges M, Jørum E, Handwerker H, Torebjörk E (2003) Pathological C-fibres in patients with a chronic painful condition. Brain 126:567-578. CrossRef Medline

Tsujino H, Kondo E, Fukuoka T, Dai Y, Tokunaga A, Miki K, Yonenobu K, Ochi T, Noguchi K (2000) Activating transcription factor 3 (ATF3) induction by axotomy in sensory and motorneurons: a novel neuronal marker of nerve injury. Mol Cell Neurosci 15:170-182. CrossRef Medline 